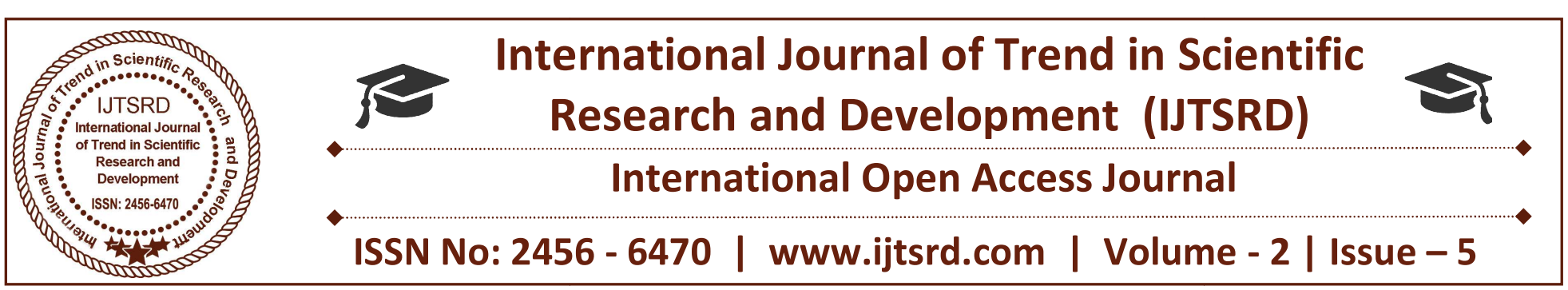

\title{
Health, Hygine and Health Care Among Rural Women in Cuddalore District
}

\author{
Maya Raveendran ${ }^{1}$, Dr. Kirubakaran Samuel ${ }^{2}$ \\ ${ }^{1} \mathrm{Ph} . \mathrm{D}$ Research Scholar, ${ }^{2}$ Professor \& Head \\ Department of Sociology, Annamalai University, \\ Chidambaram, Tamil Nadu, India
}

\begin{abstract}
The present study aimed to know the "health, hygine and health care among rural women in Cuddalore district". 100 samples were selected stratified random in Cuddalore district. Samples were selected from rural area. 100 samples are selected, 25 from each area. An analysis of the problems faced by rural women about general health would help us to reorient our health programmes in a meaningful way. Most of the beneficiaries faced problems regarding inaccessible health education, low income, high cost of nutritive foods in maintaining health practices. Hygiene awareness plays an important role in preventing various communicable diseases It demands the, concerns to provide proper education, low cost technology and strengthening the existing health facilities. health awareness among health care facilities in rural women. Hence, the most of the respondents are drinking water have high health awareness among health care facilities in rural women.
\end{abstract}

Keywords: health, hygine, health care, rural women.

\section{INTRODUCTION}

Rural women are considered as back bone of Indian economy as such they play an important role not only in maintaining their home but also managing their farms and animals, depending upon the situational, personal and socio-economic characteristics of the family to which they belong and they have no role in decision making (Patki and Nikhade 1999). In addition the health of women is the concern of the family and community and is very essential for the healthy life of a community. One of the major concerns of health is mental soundness of an individual. When the mental condition of women is good, she may take up various responsibilities of a family and herself. She may understand the complications, try to solve them, plan for future and may become mentally strong. Health has been defined by WHO as a state of complete physical, mental and social well being, and not mere complete absence of disease. Health cannot be given or distributed, but has to be actively acquired and won. Health is the natural state of a living organism. It means if a person is not in the least affected by any disease, he is called healthy. In other words, a man is said to be healthy when he has got no bodily pain or disease. Health is one of the fundamental human rights. The international/ organisation like the United Nations and the WHO have endorsed. Health is primarily personal responsibility and demands personal care to enjoy it. Knowing this importance various efforts were initiated to tackle this wide concern issue through different programmes by different agencies. Similarly the advances in Medical Sciences have the treatment for many diseases possible and simple and evolved scientific health practices to overcome many health problems. Even then the benefits of Modern Medicines have not reached the vast majority of people in poverty groups and rural area. Since $80.3 \%$ of Indian population is living in rural area as against $26.7 \%$ in urban area Health problems all over the world in countries with different levels of technical development are closely connected to the vulnerability of the mother child dyad to inadequate or in appropriate nutrition, infection, unregulated fertility and other factors. Grover (2002) carried out a study on dietary intake and socio-economic factors in birth-weight of infants in rural Haryana and concluded that birth weight is directly influenced by income and educational level. Caste, occupation and 
family type did not bear a close relationship with birth weight $73.8 \%$ of the mothers had low hemoglobin level and were anemic. The infant is completely dependent on the mother for his or her nutrition. The diet consumed by the women and her health practices has a definite effect on her health. Malnutrition of rural mother is very common in India has pointed out that malnutrition of mother is the biggest single cause of infant and maternal mortality, therefore, an improvement in the nutritional status of such mothers is of paramount importance. Because specially a rural woman plays a multiplicity of roles in addition to baby rearing and milk production. She is an essential component of the country's agricultural economy, one needs to ensure that her capacity for work has not been compromised. Maintaining an optimum nutritional status of the women, her health practices and hygeine is the first step towards uplifting the socioeconomic status of our population as a whole. In the year 2005, W.H.O. has given a slogan for world health Day i.e. 7th April, 2005 "Make every mother and child count." This shows the serious concern of International Welfare Agencies with the health of women and children in general and low status illiterate rural women and their malnourished children in particular. The women who are the prime producer of the necessities of life, women on whom the society depends so heavily for economic support and family health care, hence it is important to study their current problems regarding maintenance of required health and hygiene within their existing socio-economic backgrounds.

\section{REVIEW OF LITERATURE}

Shubhangna Sharma (2009) Adolescent girls of age 13 to 19 years constitute nearly 66 million of population in India. The lives of these girls are characterized by limited education, lack of knowledge pertaining to social as well as health aspects and also limited influence on decisions affecting their lives. Thus, awareness is one major factor for development of this group of population because of the fact that these adolescent girls would be the future housewives. A study was undertaken to see the awareness of adolescent girls regarding health aspects through an intervention study. The study adopted a pretest - post test design with an intervention for a specific period. A total of 112 adolescent girls in the age group of 14 to 18 years were selected randomly from government schools of five villages in two blocks of Kangra district of Himachal Pradesh. The tools for assessment consisted of socio-economic status scale and a general awareness scale. The sample group was pretested on their level of general awareness which focused specifically on health aspects. An intervention package was developed on the aspects of health including general health, reproductive and child health, environmental health and nutritional aspects. The intervention was given for nine months to the girls though lectures, discussions and demonstrations. Post testing was done on the girls after the period of intervention. Results showed that the knowledge of girls regarding health aspects improved significantly after intervention. There was a considerable increase in the awareness levels of girls with regard to knowledge of health problems, environmental health, nutritional awareness and reproductive and child health. Thus informative and educable intervention seem to have a positive effect on awareness levels which would eventually encourage expansion of knowledge and positive health habits.

Monika Panchani (2014) "You can tell the condition of the nation by looking at the status of women."Jawaharlal Nehru .Women's empowerment is vital to sustainable development and the realization of human rights for all. When women are empowered, whole families benefit, and these benefits often have ripple effects to future generations. But the study of women's empowerment has raised a lot of concerns and issues that are associated with other demographic and health outcomes. The WHO constitution states: "The enjoyment of the highest attainable standard of health is one of the fundamental rights of every human being without distinction of race, religion, political belief, economic and social condition." A major obstacle to enjoying the right to health is being born female. Women's health is of crucial importance, which is greatly affected by the ways in which they are treated and the status they are given in the society as a whole. Studies have indicated that women are biologically and epidemiologically more vulnerable to diseases. Primary health care relies heavily on the contributions of women, particularly in the area of health education, it raises their self-esteem and empowers them to serve their communities in a number of ways: by improving women's health and the health of their families and by training women both as care givers and as health educators. An attempt has been made to study the role of PHC in providing the health needs of its most vulnerable and needy populations and, at the same time, empowers its most neglected resource - women. 


\section{METHODOLOGY}

Simple random samples. 100 samples were selected.

\section{OBJECTIVES}

1. To identify the health care facilities available in the selected area.

2. To know the knowledge about health care among the respondents.

\section{HYPOTHESIS}

1. There is no association difference between monthly income wise classification based on sanitation.

\section{Sampling Technique}

Samples were selected from rural area. 100 samples are selected, 25 from each area.

\begin{tabular}{|l|l|}
\hline \multicolumn{2}{|c|}{ Area } \\
\hline Killai & 25 \\
\hline MGR Thittu & 25 \\
\hline Pudusattiram & 25 \\
\hline Pitchavaram & 25 \\
\hline Total & 100 \\
\hline
\end{tabular}

\section{Method of Data collection}

To collect the primary data standard questionnaires were used. The tools were circulated among the selected respondents and interview method also adopted.

\section{Statistical tool used}

The following statistical tools were used to analyze the data. They were

$>$ F-test

$>$ Chi square test are used

\section{RESULT AND DICUSSION}

Table: 1 Health awareness among health care facilities in rural women in Cuddalore district

\begin{tabular}{|l|c|c|c|c|}
\hline \multicolumn{1}{|c|}{ Opinion } & Mean & S.D & $\begin{array}{c}\text { F- } \\
\text { value }\end{array}$ & P-value \\
\hline $\begin{array}{l}\text { Sanitation } \\
\text { facilities }\end{array}$ & 3.46 & 0.59 & & \\
\cline { 1 - 3 } $\begin{array}{l}\text { Drinking } \\
\text { water }\end{array}$ & 6.98 & 0.87 & & \\
\cline { 1 - 3 } $\begin{array}{l}\text { Clean } \\
\text { environment }\end{array}$ & 4.67 & 0.96 & \multirow{2}{*}{8.39} & $\begin{array}{c}0.001 \\
\text { Significant }\end{array}$ \\
\cline { 1 - 3 } Nutrition & 2.59 & 0.49 & & \\
\cline { 1 - 2 } $\begin{array}{l}\text { Basic } \\
\text { education } \\
\text { about health } \\
\text { care }\end{array}$ & 1.98 & 0.63 & & \\
\hline
\end{tabular}

Ho: There is no significant difference between Health awareness among health care facilities in rural women's.

The table 1 exhibits the details of Mean, S.D. and Fvalue for respondents health awareness among health care facilities in rural women. It is inferred from the obtained F-value there is a significant difference in respondents level of Health awareness among health care facilities in rural women. Since the calculated Fvalue (8.39) which is significant at 0.001 level. Therefore the stated null hypothesis is rejected and alternate hypothesis is accepted. Therefore it is concluded that respondents differ in their level of Health awareness among health care facilities in rural women. Hence, the most of the respondents are drinking water have high mean value for Health awareness among health care facilities in rural women's.

Table: 2 Chi square test between monthly income wise classification based on sanitation

\begin{tabular}{|c|c|c|c|}
\hline \multirow[b]{2}{*}{ Monthly income } & \multicolumn{2}{|c|}{ Sanitation } & \multirow[b]{2}{*}{ Total } \\
\hline & Yes & No & \\
\hline Below 15,000 & 19 & 39 & 58 \\
\hline $15,001-30,000$ & 36 & 6 & 42 \\
\hline Total & 55 & 45 & 100 \\
\hline \multicolumn{4}{|c|}{2} \\
\hline \begin{tabular}{|l|l|} 
Chi square & $\mathrm{df}$ \\
\end{tabular} & & $\overline{P-v a l}$ & \\
\hline 15.98 & 0.001 & Signi & \\
\hline
\end{tabular}

Ho: There is no association between monthly income wise classification based on sanitation.

The above table shows the chi square test between monthly income wise classification based on sanitation. From the above table, in the below 15,000 income group, 19 respondents are yes, 39 respondents are no. Further in 15,001-30,000 income group, 36 respondents are yes sanitation and 6 respondents are no sanitation.

The Chi square test is applied for further discussion. The calculated chi square value 15.98 at 3 degrees of freedom is significant at 0.001 level. Therefore, it is concluded that the alternative hypothesis that "there is an association between respondents' monthly income wise classification based on sanitation" is accepted. Therefore, the null hypothesis is rejected. 
Table: 3 Chi square test between education qualification wise classification based on health care

\begin{tabular}{|l|l|l|l|}
\hline \multirow{2}{*}{$\begin{array}{c}\text { Education } \\
\text { qualification }\end{array}$} & \multicolumn{2}{c|}{ Health care } & \multirow{2}{*}{ Total } \\
\cline { 2 - 3 } & 18 & 12 & 30 \\
\hline Below SSLC & 7 & 5 & 12 \\
\hline HSC & 8 & 0 & 8 \\
\hline Degree & 5 & 45 & 50 \\
\hline Illiterate & 38 & 62 & 100 \\
\hline Total & & & \\
\hline
\end{tabular}

\begin{tabular}{|c|c|c|}
\hline Chi square & df & P-value \\
\hline 23.64 & 5 & 0.001 Significant \\
\hline
\end{tabular}

Ho: There is no association between education qualification wise classification based on health care. The above table shows the chi square test between education qualification wise classification based on health care. From the above table, in the below SSLC group, 18 respondents are high, 12 respondents are average. Further in HSC group, 7 respondents are high and 5 respondents are average. In degree group, 8 respondents are high. Also in illiterate group, 5 respondents are high, 45 respondents are average. Therefore it is concluded that illiterate group have high total respondents.

The Chi square test is applied for further discussion. The calculated chi square value 23.64 at 5 degrees of freedom is significant at 0.001 level. Therefore, it is concluded that the alternative hypothesis that "there is an association between respondents' education qualification wise classification based on health care" is accepted. Therefore, the null hypothesis is rejected.

Table: 4 Showing mean, S.D and P-value for respondents opinion about drinking water based on community

\begin{tabular}{|c|c|c|c|c|}
\hline Community & Mean & S.D & F-value & p-value \\
\cline { 1 - 3 } SC/ST & 7.59 & 1.50 & & \\
\cline { 1 - 3 } MBC & 3.18 & 1.23 & \multirow{2}{*}{6.94} & $\begin{array}{c}0.001 \\
\text { Significant }\end{array}$ \\
\cline { 1 - 3 } BC & 4.52 & 1.27 & & \\
\hline Others & 2.31 & 0.89 & & \\
\hline
\end{tabular}

Ho: There is no significant difference between drinking water based on community.

The table 4 exhibits the details of Mean, S.D. and Fvalue for respondents about drinking water based on community. It is inferred from the obtained F-value there is a significant difference in respondents level of drinking water based on community. Since the calculated F-value (6.94) which is significant at 0.001 level. Therefore the stated null hypothesis is rejected and alternate hypothesis is accepted. Therefore it is concluded that respondents differ in their level of drinking water based on community.

\section{FINDINGS}

$>$ Result proved that respondents differ in their level of Health awareness among health care facilities in rural women. Hence, the most of the respondents are drinking water have high mean value for health awareness among health care facilities in rural women.

There is an association between respondents' monthly income wise classification based on sanitation".

Survey exhibits that there is an association between respondents' education qualification wise classification based on health care".

Analysis shows that respondents differ in their level of drinking water based on community.

\section{CONCLUSION}

The present study aims to develop health, hygine and health care among rural women in cuddalore district. 100 samples were selected stratified random in Cuddalore district. Samples were selected from rural area. Health awareness among health care facilities in rural women. Hence, the most of the respondents are drinking water have high health awareness among health care facilities in rural women. Awareness generation at various levels is very much essential to prevent infections and various communicable diseases.

\section{REFERENCE}

1. Ariana, Proochista and Arif Naveed(2009). An Introduction to the Human Development Capability Approach: Freedom and Agency. London: Earthscan. 228-245

2. Chow, Clara, and Anushka, Patel (2012). "Women "s cardiovascular health in India." J.Heart.: 456-459. Web. 7 February 2013. 
3. Grover (2002) Please understand when I cry out in pain: women's accounts of maternity services during labour and delivery in Ghana. BMC Public Health. 22(140).

4. Monika Panchani (2014) Role of Primary Health Care in the Empowerment of Women and Concern about Health Issues. International Journal of Research Studies in Biosciences (IJRSB) Volume 2, Issue 11, December 2014, PP 21-27.
5. Patki and Nikhade (1999) A Cross Sectional Study on Awareness about Menstrual Hygiene among Rural Women, Stanly Medical Journal, Vol. 2, Issue. 2.

6. Shubhangna Sharma (2009) Health Awareness of Rural Adolescent Girls: An Intervention Study. J Soc Sci, 21(2): 99-104 (2009).

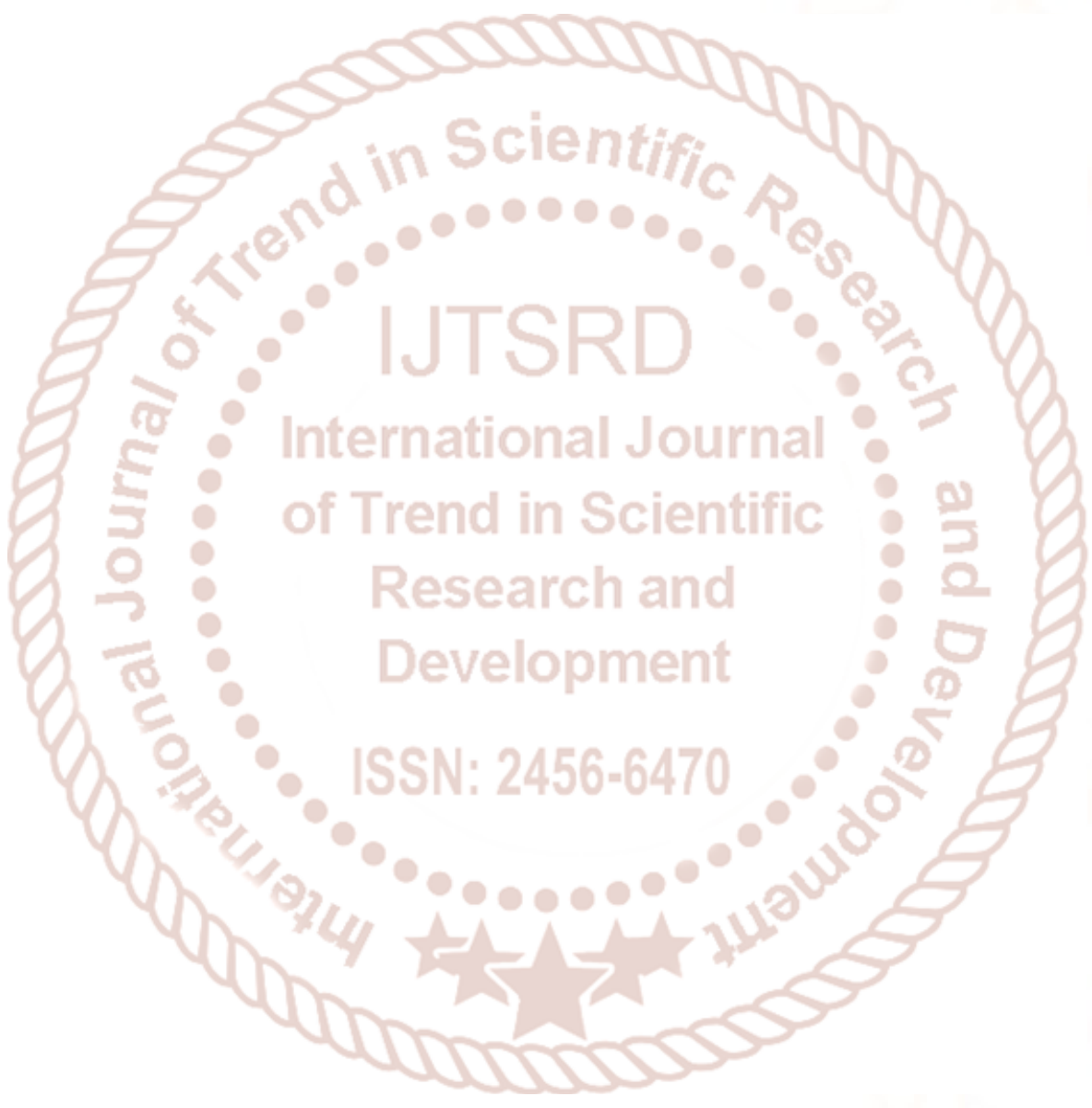

